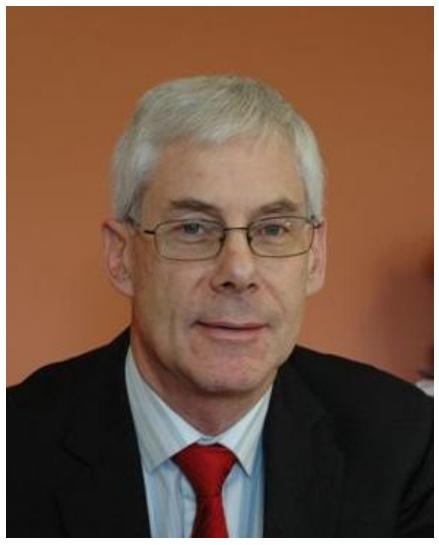

\title{
REAL WAGES AND PRODUCTIVITY IN NEW ZEALAND
}

\author{
Bill Rosenberg \\ New Zealand Council of Trade Unions Te \\ Kauae Kaimahi \\ Wellington
}

\begin{abstract}
The standard neo-classical model implies that the real wage should equate to the marginal product of labour, and therefore wages should, at least in the long run, rise at the same rate as labour productivity. That also underlies much of the politics of wage setting. This paper investigates the empirical relationship between real wages and labour productivity in New Zealand. It first looks at the labour share of income (GDP) and finds that the share has fallen in recent years indicating that real wages are also falling behind increases in labour productivity. It then considers variants of three wage measures that are available: the average hourly wage, the Labour Cost Index and the Compensation of Employees measure which is part of the National Accounts. In real terms, increases in the average wage and in the Compensation of Employees measure fall well behind increasing labour productivity. An analytical (non-official) series of the LCI measures tracks productivity very closely whereas the published LCI is essentially flat or falling when deflated. The paper concludes that real wage rises vary widely from labour productivity increases even over several business cycles. This has implications for wage setting, for the measurement of wage rates and productivity, and for the economic and wage models tested.
\end{abstract}

\section{Introduction}

Productivity is a focus of extensive economic study, particularly with regard to economic growth. Paul Krugman's statement that 'Productivity isn't everything, but in the long run it is almost everything" (Krugman, 1997, p. 11) is frequently quoted. The New Zealand Treasury goes as far as to assume, as part of its long term modelling of the New Zealand economy, that "inflationadjusted wage growth in the private sector matches labour productivity growth" (New Zealand Treasury, 2009, p. 71). The growth models of Robert Solow and others provided a means to integrate the concept into economic growth theory. In these models, productivity takes three forms: labour, capital and "multifactor" productivity.

The growth models, like other neo-classical models of the labour market, imply that under their usual assumptions including perfectly competitive labour and product markets, and perfect access to and use of information, real wage rates (i.e. rates per unit time corrected for price levels) will be equal to the value of the marginal product of labour at the price expected by the employer for its output. If this is correct, real wages should rise in proportion to marginal labour productivity.

However this is a theoretical model of wage setting and many other theoretical models exist. They need to be tested empirically. The implications of a link between wage rates and productivity are manifold and important.
For example Krugman's statement implies a link between incomes and productivity. Treasury's explicitly assumes there is one. While productivity places a long-term limit on how quickly incomes in a country can rise, that says nothing about the distribution of those incomes with the country nor about the possibility of shorter term variations from the limit. It is conceivable for example that while productivity increases strongly, wages stagnate due to the institutional situation (such as the bargaining power of wage earners) in the country, with the increased income available going to owners of capital, or vice versa. It is stating the obvious to say that wages are a contested issue between capital and labour and their relative power must have an effect on wage setting.

This paper examines the relationship between wages and productivity in New Zealand over the last 20-30 years. It proceeds as follows. We first consider the theory behind productivity and wage setting. We then consider the different measures of productivity and wages available for New Zealand and describe their characteristics. The available data is then presented and we conclude with a discussion of the findings and areas for further research.

\section{Theory}

Neo-classical economics provides various derivations of the relationship between wages and productivity. The general reasoning it gives is as follows. Assume a firm 
produces products at a price $p$ per unit of output, and that there is perfect competition in the product market, so firms are price-takers: they must accept that price. The firm's inputs are labour and capital. Given a particular capital structure, the firm will take on labour, raising the offered wage rate in order to attract more workers, to the point where it has maximised its profits. If the wage rate at that point is $w$ then the standard condition for profit maximisation under perfect competition is that the marginal cost of a further unit of production is equal to the value of that production. A further unit of production would require the firm to pay a higher wage than $w$ in order to extract more work from the workforce, and it therefore would make a loss on that unit. Producing less would leave profits unexploited. Note that this result also relies on perfect competition in the labour market. It is assumed that workers will work if paid more than some minimum "participation wage" and that the higher the wage, the more workers will be enticed into the firm's workforce. The firm must pay that much because otherwise workers will immediately go to another firm. Workers will take up and leave jobs with no delay, cost or regret, and have perfect information about wages in other firms.

In mathematical terms, it is useful to express this in terms of the Solow growth model (see for example Jones, 1998, p. 20). In its simplest form, it is assumed that there is a production function $F(K, L)$ where $K$ is the amount of capital employed and $L$ the amount of labour (number of hours, say). Then output $Y$ is

$$
Y=F(K, L)
$$

The firm pays $w$ for each unit of labour and $r$ for renting each unit of capital for a given period. Its costs $C$ are therefore the total cost of renting its capital, $K r$, plus its wage bill, $L w$.

$$
C=K r+L w
$$

Its income is $Y p$ - the value of its production assuming it can sell all it produces. Maximising profit $\pi$ therefore maximises

$$
\pi=Y p-C=F(K, L) p-K r-L w
$$

Maximising for $L$, the amount of labour utilised by the firm,

$$
\frac{\partial \pi}{\partial L}=\frac{\partial F\left(K_{,} L\right) p}{\partial L}-W=0
$$

So

$$
\frac{W}{p}=\frac{\partial F\left(K_{y} L\right)}{\partial L}
$$

The left hand side is the real wage and the right hand side is the marginal productivity of labour, proving the neoclassical result.
Note that marginal labour productivity still depends in general on both capital and labour inputs. So a worker doing nothing substantively different in her job could still have improving labour productivity if capital is added and under neo-classical assumptions should be receiving a higher wage as a result. For example a bus driver's productivity may increase as a result of her bus being replaced by a larger one.

In fact, the simple growth model is augmented by a third factor in addition to capital and labour, to reflect improvements in technology and workers' skills over time. Increased productivity from such sources is called multifactor productivity. The additional factor does not change the derived relationship between wage rates and productivity. In practice it is very difficult to measure multifactor productivity directly and is calculated as a residual of productivity unexplained by labour and capital. It is therefore in practice liable to absorb any errors in modelling, be sensitive to specification of the production function, and contain other unobservable effects.

Three features are significant in choosing appropriate data for testing the result empirically. Firstly, the real wage is expressed in terms of the price received by the firm for its product - or more accurately, the price it anticipates it will receive for its product - not the price level faced by the worker. Secondly, growth models normally assume a Cobb-Douglas production function with constant returns to scale (so a doubling of both labour and capital doubles production). Under these circumstances, the real wage is proportional to average labour productivity, so it does not matter if we measure marginal labour productivity (the product of one extra hour worked in the firm) or average labour productivity (the product of an average hour worked) if we are considering only changes in wages and productivity. Finally, the wage $w$ represents the cost to the employer of employing the worker. It should therefore in practice include non-wage labour costs.

Finally, a decomposition of output proves useful as a way to look at the relationship between wages and productivity. According to the above derivation, at profit maximisation, the value of total output $Y p$ is equal to the labour share of income, $L w$, plus the capital share, $K r$. These are calculated independently for the National Accounts. If we call the shares of income expressed as a proportion of the total $L S$ and $K S$ respectively, then

$L S=\frac{L w}{Y_{p}}=1-\frac{K r}{Y_{p}}=1-K S$

But

$\frac{L w}{Y p}=\frac{w}{p} / \frac{Y}{L}$

So $L S$ is the ratio of the real wage and average labour productivity, $Y / L$. 
There is a difficulty in measuring this in practice. Some labour is carried out by working proprietors who also receive income from the capital invested in their enterprises. Their labour income is therefore not observable and the output due to their labour is not separable from the output of their employees in the national accounts. It is however possible to estimate the hours they work. Their labour income is estimated by assuming they receive the same average rate per hour as employees in the same industry (Statistics New Zealand, 2010 b, p. 20). In what follows we therefore consider the labour share including working proprietors. This is sometimes called the Unit Labour Cost, or Real Unit Labour Cost for the deflated version we are using (Australian Bureau of Statistics, 2006). The Australian Bureau of Statistics and the OECD among others publish such series. Since working proprietors' average wages are assumed to be the same as that of employees in their respective industries, this is still a useful measure of the relationship between wage setting and productivity. If this assumption was not made, the measure would present some difficulties as it is not obvious that working proprietors would set their own pay on the same basis as for employees. The required data is available in SNZ's Industry Productivity Statistics (Statistics New Zealand, 2010a).

The neo-classical model of wage setting has been found wanting in numerous ways. There are many alternative models that take into account the unequal relationship between employer and worker, imperfect information, union activity, employer desires to retain skilled and experienced employees and reduce hiring costs among the many deviations from perfect markets. Ricardo and Marx regarded the labour market as being governed not primarily by productivity but by the supply of labour as determined by the minimum income required for a worker to "rear a family" and thereby maintain the size of the labour force (see for example Chapter 7 of Rowthorn, 1980). Stiglitz has considered the effect of information imperfections (Stiglitz, 1985). There are models that take into account bargaining theory including decentralisation (such as Conway, 1999), and there are many other examples. The neo-classical model is therefore highly contested and there are alternative explanations for wage setting.

\section{Measures of productivity and wages}

Statistics New Zealand (SNZ) publishes annual indexes for labour, capital, multifactor and related productivity measures going back to 1978. Details of their construction are available in an SNZ publication (Statistics New Zealand, 2010b). The series covers a subset of industries for which SNZ considers it is possible to construct valid productivity measures. This is called the "measured sector" which in 2006 constituted about $74 \%$ of GDP and excludes the ANZSIC 1996 private sector industries of Property services and Ownership of owner-occupied dwellings, and the mainly public sector industry classifications of Central government administration and defence, Local government administration, Education, and Health and community services. The excluded private sector industries have a variety of difficulties, which SNZ is working to resolve, including some that have no or very little labour input. The public sector "industries" provide services that are mostly free or at nominal cost. SNZ is working on other measures of output for the Education and Health sectors.

Two sectors have been included only since 1996: Business services and Personal and other community services. The industries included in productivity measurement before 1996 are referred to as the "former measured sector". While the discontinuity in 1996 may not be a problem for productivity measurement, there are indications it made a small but material change relevant to capital and labour income shares. SNZ notes with respect to capital and labour shares of income, "a small level shift in the series in 1996 [which] is due to the introduction of business services, and personal and other community services into the measured sector" (Statistics New Zealand, 2010c, p. 22). We therefore use the former measured sector in this analysis. In 2006 it constituted about $63 \%$ of GDP.

The assumptions underlying SNZ's construction of the productivity indexes are of significance. They follow OECD guidelines and common international practice. The various indexes are built upon Solow's model as outlined above, with the same assumptions regarding markets and the production function. Calculation of multifactor productivity requires the creation of a composite input index aggregating the labour and capital factors of production. This requires assumptions that the production function is of a particular form (namely Cobb-Douglas with constant returns to scale) and that there are perfectly competitive markets. The latter assumption is made specifically so that it can be further assumed that "real payments to capital and labour are equal to their respective marginal products" (Statistics New Zealand, 2010 b, p. 34). This in turn allows "growth accounting" which breaks down total output growth into contributions from capital, labour and multifactor productivity, and breaks down labour productivity into contributions from multifactor productivity growth and changes in the weighted capital:labour ratio. The validity of all of these indexes is therefore dependent on the relationship between wages and labour productivity.

Further, the labour input index aggregates industry inputs by weighting them by nominal labour income in the industry expressed as a share of the measured sector (Statistics New Zealand, 2010b, p. 19). While this is not as strong an assumption as that asserted by the neoclassical model, it still assumes a relationship between wages and output which may not hold and could amplify the effect of any error.

There are three measures of wages with sufficiently long series to be useful in this analysis. Each has variants.

The average wage is calculated from data collected in the Quarterly Employment Survey (QES) by taking the total earnings of employees of surveyed businesses and dividing by total hours paid. It is available for both 
ordinary time hours and all hours including overtime. It does not include non-wage earnings such as superannuation payments or ACC levies. The QES excludes a number of sectors, the most significant being agriculture and fishing. The measure reflects actual amounts paid, but has the feature that it changes with composition of the labour force. For example, an increase in numbers employed or hours worked in retailing (one of the lowest paid industries) compared to finance and insurance (one of the highest) would result in the average wage reducing even though wage rates in any given industry had not changed. While the composition effect can be a disadvantage for some purposes such as measuring the movement in wage rates, the measure does reflect the actual rate of payments made by employers for the production generated by their employees. It is not available for the measured sector before 1989 .

A similar measure is that of Compensation of Employees (COE), which is an aggregate calculated for the National Accounts. It is a wider measure of labour income which covers all sectors of the economy and includes payments "whether in cash or in kind (such as fringe benefits)" and "includes contributions paid on employees' behalf to superannuation funds, private pension schemes, the Accident Compensation Corporation, casualty and life insurance schemes, etc" (Statistics New Zealand, n.d.). The National Accounts allow it to be calculated for the measured sector back to 1972 , but suitable data to calculate it per hour are available only from 1978.

Neither of these measures includes the labour component of the income of working proprietors. For productivity calculations, it is assumed that the wage rates of working proprietors are the same as those for employees in the same industry (Statistics New Zealand, 2010b, p. 20). However in this analysis, other than for the Labour Share analysis noted above, we have deliberately excluded such labour because there is no reason to assume that self-paid labour income is set in the same way as for employees. To the extent that productivity measures include working proprietors, this is a problem. In effect we implicitly assume that their labour productivity is the same as that of employees.

The third measure is the Labour Cost Index (LCI). This is designed to sit alongside other price indexes such as the Consumer Price Index and Producer Price Index. As an index it measures changes in labour costs rather than levels of costs, and it has three main forms. One (published quarterly) measures changes in wage and salary rates, with and without overtime. An "all labour costs" index is published annually including in addition to wages and salaries, costs of annual leave and statutory holidays, superannuation, Accident Compensation Corporation employer premiums, medical insurance, motor vehicles available for private use, and low interest loans. The third form is the "unadjusted" LCI, which is based on ordinary time pay and is currently an "analytical" series (not an official published series). All LCI series except the unadjusted LCI have recently become available for the measured and former measured sector, but only from June 2001. We use the private sector version of the LCI where the measured sector breakdown is not available. As a comparison, from June 2001 to 2009, the private sector all labour costs LCI rose $23.7 \%$, and the measured sector and former measured sector LCIs rose $23.2 \%$ and $23.1 \%$ respectively.

The factors which differentiate the "adjusted" LCI (the first two forms) from the "unadjusted" are important. The adjusted LCI is intended to be a "constant quality" index in that it measures "changes in pay rates for a fixed quality and quantity of labour input. This means that all movements in salaries or wages due to quality or quantity reasons are not shown in the index, while price-related changes are." Changes regarded as "price-related" cover cost of living, matching market rates, retaining staff, attracting staff, collective employment agreements, and minimum wage changes. These are reflected in both indexes. On the other hand, the unadjusted LCI also allows for changes in pay rates due to "quality" including changes in performance, promotion, qualifications, duties or type of work, responsibilities, level of experience or length of service. In both cases, positions rather than employees are tracked by the index, but the adjusted LCI will more frequently follow the pay path of an individual employee as she is recognised for experience, performance, qualifications or additional responsibilities in a tracked position. However not all such changes will be picked up because some positions are described by a point on a pay scale. In addition, it may not be representative of staff turnover and the changes in pay rates that may bring about. These prove to be important issues to which we will return. However the unadjusted LCI does reflect changes in the "quality" of employees in a position whereas the adjusted LCI does not (Statistics New Zealand, 2010d).

Finally, the price index used to calculate the real wage from the point of view of the employer is the Producer Price Index Outputs Index (PPO). It is not available for solely the measured sector, but as it covers only "market" industries (and not government administration, health or education for example) the match is likely to be close.

\section{Results}

The most rigorous productivity measures available are indexes only. We therefore can compare only changes in wages and productivity - in other words, the elasticity of wages with respect to productivity.

However there is an intuitive but less rigorous approach to productivity measurement that allows a comparison between levels of wages and productivity levels which is illustrative to begin with. As noted above we can use the Labour Share of GDP as a measure of the ratio of the real wage to productivity. This is plotted in Error! Reference source not found. for the former measured sector. A trend line is drawn for the period 1978 to 2006 which spans 6 full economic cycles (see Statistics New Zealand, 2010c, p. 3 and below). The Labour Share of the part of added value (GDP) in the measured sector has fallen over the 28 years at a rate of 0.37 percentage points a year, or 
10.3 percentage points over the 28 years. From peak to trough it has fallen by $15.7 \%$ from $65.5 \%$ of measured sector GDP in 1981 to $53.7 \%$ in 2002.

In other words, real wages have been rising appreciably more slowly than productivity measured as added value per hour worked. The change implies that the assumption of constant returns to scale is not correct.

During the two business cycles spanning 1990-2000 which largely coincide with the Employment Contracts Act 1991, the trend showed a faster fall of 0.39 percentage points a year although the Labour Share actually fell 4.9 percentage points from $61.6 \% \%$ to $56.7 \%$. During the following business cycle from 2000 2006, largely coinciding with the Employment Relations
Act 2000, the trend line was flat, although Labour Share bottomed out at $53.7 \%$ in 2002 (18 months after the Act came into force) and rose to $55.7 \%$ from 2002 to 2006 .

We now turn to the official measure of productivity and the wage measures discussed, always for the former measured sector. We consider the period 1978-2006, or shorter periods according to the availability of data. They are tabulated over "peak to peak" business cycles identified during the period by SNZ, which states: "Estimating growth over business cycles is preferable as it accounts for changes in capacity utilisation rates over the period of a business cycle" (Statistics New Zealand, 2010c, p. 2).

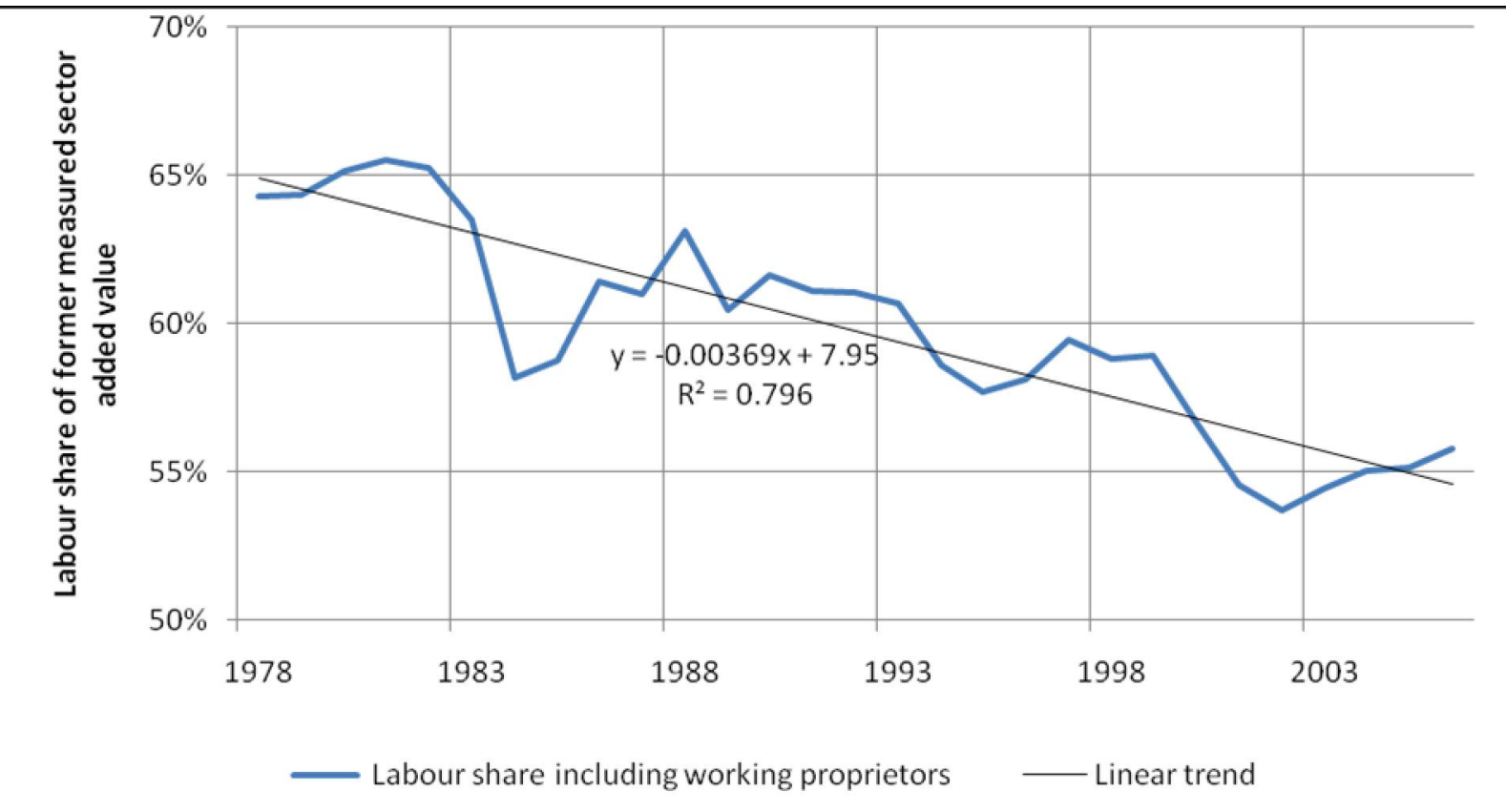

Figure 1. Former Measured Sector 1978-2006: Labour Share of value added (including labour of working proprietors), and trend line for Labour Share. (Source: National Accounts and Statistics New Zealand, 2010a)

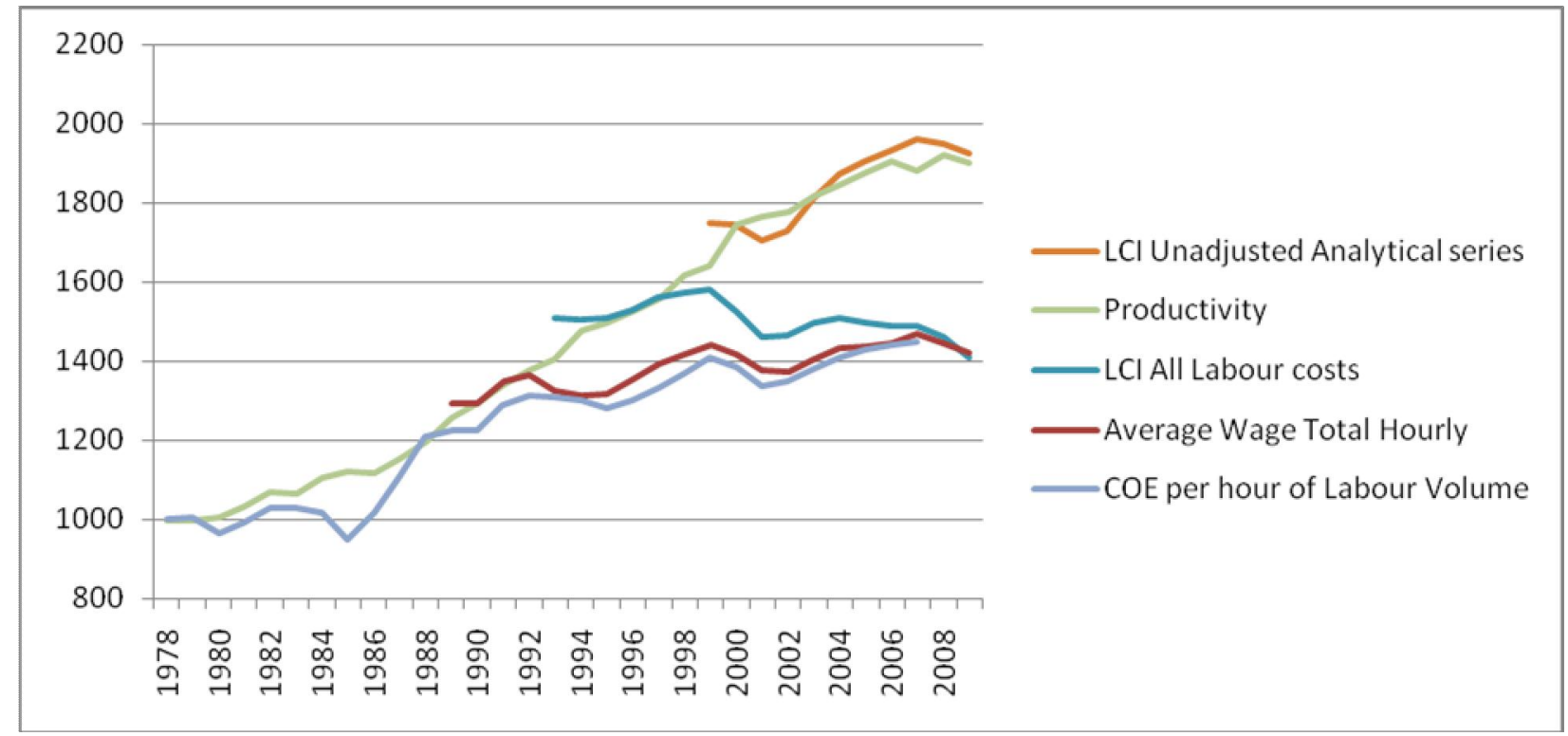

Figure 2. Different real wage measures versus labour productivity for the former measured sector. The real wage measures are re-based to the level of the labour productivity index in the first year of the first cycle for which they are first available. 
Four measures of real wages are tabulated in Error! Reference source not found.. Others are not included because the results are very similar. For example, the real ordinary time average wage rose 14\% 1989-2006; the real total hourly average wage rose $12 \%$. We use the latter because it is more complete. The three official LCI measures all fell $2 \%$ in real terms between 1992 and 2006. We use the LCI all costs index because it is most complete. Wage rates are calculated from the COE (we call it COE/LV) using a "labour volume" series which SNZ has developed to construct a labour input index for labour productivity. SNZ kindly provided it excluding working proprietors.

Unless otherwise stated, the PPO is used as the price index.

Elasticities of real wages with respect to labour productivity are given for each measure over each business cycle and for the whole period. If the neoclassical model were correct, we would expect them to be 1.0 (wages would rise at the same rate as labour productivity). They vary considerably from that. Only the unadjusted LCI gets close to 1.0. All vary considerably between business cycles.

Figure 2 illustrates this. Each real wage series is re-based to start on the labour productivity curve from the first year of the first business cycle it was available. Only the unadjusted LCI stays close to the productivity curve.

The average wage rises by only a quarter $(0.25)$ of the increase in productivity over the cycles it is measured (1990-2006). In real (PPO) terms it rose $11.6 \%$ while labour productivity rose $47.1 \%$. From a worker's viewpoint, in real CPI terms the real wage rose $7.7 \%$.

\begin{tabular}{|c|c|c|c|c|}
\hline \multicolumn{5}{|c|}{ Real wages compared to labour productivity } \\
\hline \multirow{2}{*}{$\begin{array}{l}\text { Former measured sector } \\
\text { Cycle }\end{array}$} & \multirow{2}{*}{$\begin{array}{c}\text { Average } \\
\text { wage } \\
\text { Total } \\
\text { hourly }\end{array}$} & \multirow{2}{*}{$\begin{array}{c}\begin{array}{c}\text { Compensation } \\
\text { of Employees }\end{array} \\
\begin{array}{c}\text { Hours from } \\
\text { Labour } \\
\text { Volume }\end{array}\end{array}$} & \multicolumn{2}{|c|}{ Labour Cost Index } \\
\hline & & & $\begin{array}{c}\text { All } \\
\text { labour } \\
\text { costs }\end{array}$ & Unadjusted \\
\hline $1978-82$ & & 0.40 & & \\
\hline $1982-85$ & & -1.64 & & \\
\hline $1985-90$ & & 1.92 & & \\
\hline $1990-97$ & 0.37 & 0.42 & & \\
\hline $1997-2000$ & 0.14 & 0.33 & -0.18 & \\
\hline $2000-06$ & 0.23 & 0.47 & -0.26 & 1.19 \\
\hline $1990-2000$ & 0.27 & 0.37 & -0.18 & \\
\hline $2000-06$ & 0.23 & 0.47 & -0.26 & 1.19 \\
\hline \multicolumn{5}{|l|}{ All full cycles } \\
\hline From & 1990 & 1978 & 1997 & 2000 \\
\hline To & 2006 & 2006 & 2006 & 2006 \\
\hline Elasticities & 0.25 & 0.49 & -0.20 & 1.19 \\
\hline Increase in productivity & $47.1 \%$ & $90.3 \%$ & $22.1 \%$ & $9.0 \%$ \\
\hline \multicolumn{5}{|c|}{ Real wages using June 2010 PPI Outputs prices } \\
\hline Initial & 20.73 & 18.37 & 1101 & 908 \\
\hline 2006 & 23.15 & 26.52 & 1052 & 1005 \\
\hline Increase & $11.6 \%$ & $44.4 \%$ & $-4.4 \%$ & $10.7 \%$ \\
\hline \multicolumn{5}{|c|}{ Real wages using June 2010 CPI prices } \\
\hline Initial & 20.47 & 19.86 & 1025 & 860 \\
\hline 2006 & 22.06 & 25.27 & 1002 & 958 \\
\hline Increase & $7.7 \%$ & $27.2 \%$ & $-2.2 \%$ & $11.4 \%$ \\
\hline
\end{tabular}


Table 1. Elasticities of wages with respect to labour productivity, and real wage/labour cost changes. For sources see text.

The COE/LV grows faster than the average wage. Its elasticity is 0.49 for the period $1978-2006$ and 0.38 for the period 1990-2006 (matching the availability of the average wage). It is not clear why. It reflects a much broader range of wage costs than the average wage, but given the close relationship between the all labour costs LCI and the ordinary wage LCI, this is unlikely to be the cause. Possibly it is due to inconsistencies in its construction over the years, or to the construction of the labour volume measure. Even then it shows real wages capturing only $49 \%$ of labour productivity increases, and for all but 1985-90, considerably less. It was negative from 1982-85, reflecting the wage and price freeze 198284 . The high elasticity from 1985-90 may reflect a catchup under changed employment legislation. By 1988 real wages had risen as fast as labour productivity since 1978, but fell further behind almost constantly from that point. In real PPO terms the COE/LV rose $44.4 \%$ while labour productivity rose $90.3 \%$. From a worker's viewpoint, it rose $27.2 \%$.

The all labour costs LCI actually fell in real terms over each of the three cycles it was measured (1997-2006), giving a negative elasticity of 0.20 . In real PPO terms it fell $4.4 \%$ while labour productivity rose $22.1 \%$. It fell $2.2 \%$ in terms of the CPI. As noted above, this measure is designed to measure changes in wage costs for a fixed quantity and "quality" of labour. It is therefore expected that it would not reflect changes in labour productivity.

The unadjusted LCI rose more than labour productivity over the one cycle (2000-06) it was available for the former measured sector, rising $19 \%$ faster than productivity. While a superficial view would be that this shows a picture of employers rewarding employees individually for their performance, that does not recognise that the LCI survey in the end follows positions rather than individuals.

At some point, the individual employee leaves each position being tracked and a crucial question is what the employer does to replace her. Does pay revert to the base pay for the job? Employers could be expected to take such opportunities to reduce their costs. If not, and the neo-classical wage model is correct, a constantly increasing base or entry rate for each specified position would imply that employers are finding constantly more productive employees to fill their positions. That seems unlikely given complaints of skill shortages for the period covered by this measure, and the reality that not all employers can employ existing skilled workers: some workers retire or leave the country and must be replaced by relatively unskilled young workers fresh from school or tertiary education. Are employers paying more despite employing relatively unskilled workers when they re-fill a position - again in conflict with the neo-classical wage model?

On the other hand, if it does reflect reality, what are we to make of the official LCI, which shows static or falling wages for an unchanged position. It might be expected that this would reflect the "base rate" an employer would come back to when a position is vacated. If the reality is that employers are constantly increasing the pay or the skill requirements for positions when they become vacant, does the official LCI have any practical meaning?

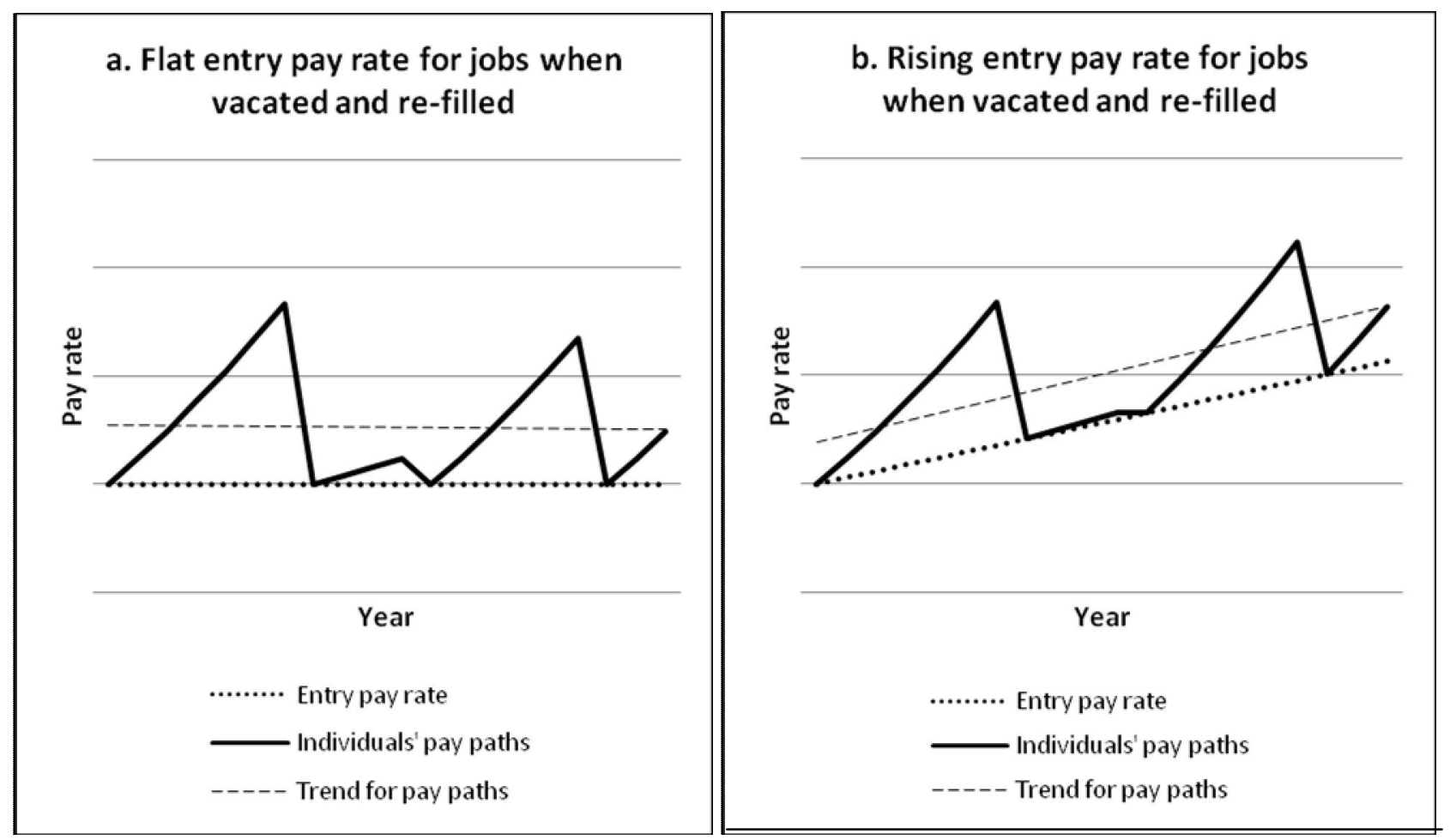

Figure 3. Schematic view of pay rates measured by the unadjusted LCI. 
Figures $3 \mathrm{a}$ and $3 \mathrm{~b}$ schematically illustrate the contrasting positions. The dotted line in each is the base rate to which a position returns when vacated. In $3 \mathrm{a}$ it is flat, as the adjusted LCI suggests is likely. The variation in rates paid shown by the unadjusted LCI is represented by the jagged line which over time and with many employees would show in aggregate as the dashed trend line. In other words, it would be expected that the unadjusted LCI would represent higher pay levels but ones that on average rise at the same rate as those in the adjusted LCI. Instead we see something like $3 b$ in which base or entry pay rates are constantly rising.

Further, if pay rates are increasing at the rate suggested by the unadjusted LCI, why is this not reflected in the aggregate-based measures such as the average wage or the COE/LV? These are increasing at significantly slower rates than the unadjusted LCI.

While there are different composition issues with regard to the aggregate-based measures as compared to the LCI, decomposing $\mathrm{COE} / \mathrm{LV}$ into individual industrial sectors provides no clues as to the difference in rate increases. Sector elasticities are available only for the period 1997 2006 due to the unavailable of sector PPOs prior to that. While the COE/LV's elasticity for the period was 0.38 for the whole measured sector, elasticities in individual sectors ranged from -20.25 in Accommodation, Cafes and Restaurants, where real wages rose $2.8 \%$ in PPO terms despite a $0.1 \%$ fall in labour productivity, to 19.7 in Petroleum, Chemical, Plastic and Rubber Product Manufacturing where real wage rises of $10.0 \%$ outpaced a labour productivity increase of $0.5 \%$. Out of 21 sectors (including both Manufacturing overall and 9 manufacturing subsectors), only one had an elasticity within $10 \%$ of 1.0 (0.93 in Machinery and Equipment Manufacturing), and one more within 20\% (0.85 in Wood and Paper Product Manufacturing). Of the 21, 16 fell in a range between 0 and 1 .

\section{Conclusions}

By most of the measures, real wage rises vary widely from labour productivity increases even over several business cycles. The measure giving most support to the neo-classical model is the unadjusted LCI, but it is difficult to reconcile this with its design and the other measures, and it has had a brief life (in practice, one business cycle) to accumulate evidence of how it will behave in the long run.

Real wages have fallen considerably behind labour productivity increases. Depending on the measure, and putting aside the unadjusted LCI because of its difficulties, New Zealand workers in the measured sector have received at most $49 \%$ of the increases in labour productivity, but probably considerably less in the last two decades. The average wage shows them receiving only a quarter of labour productivity gains. These trends have resulted in a lower labour share of the economy's output, suggesting a change in relative bargaining power. There is evidence for this in the fall in labour share during the Employment Contracts Act 1991, and its rise during the Employment Relations Act 2000.

These findings have obvious implications for wage setting. While increased labour productivity may allow larger wage increases, the labour market is not producing them - and produced less under the more free-market Employment Contracts Act. Better mechanisms are needed if productivity gains are to be passed on.

The findings also have implications for the measurement of productivity, which assumes the contested relationship between real wages and marginal productivity in order to calculate multifactor productivity and the contributing factors to both it and labour productivity. Part of the reason for the assumptions being wrong is undoubtedly in the nature of markets, but it could also be in the form of the production function (for which the changing labour share provides evidence). Further research into these matters is warranted.

The meaning and construction of the different LCI measures also deserves investigation. Confidence in them requires a greater understanding of the differences between the different LCI measures, the wage measures derived from $\mathrm{COE}$, and the average wage. Some of these issues could be investigated empirically using SNZ's Linked Employer-Employee Data (LEED) series which records earnings of new hires for example. Until these matters are clarified it would seem wise to maintain the unadjusted LCI's "analytical” status.

Finally, there needs to be deeper investigation of the substantive issue - the relationship between wages and labour productivity. One path to follow is to consider the effectiveness of the employment relations institutions. A second is to investigate more deeply the assumptions underlying wage models. Industry studies may help to identify influencing factors. Any differences due to skill and wage levels also need to be understood.

Part of the substantive issue is that the validity of the neoclassical model, including the growth model and production function, is called into question. This has much wider implications.

\section{Acknowledgements}

I am very grateful for the willing assistance of staff of Statistics New Zealand in providing data in a suitable form for this study, often under time pressure, including Brendan Mai (productivity), Litia Tapu and the Prices Team, Paul Sutherland and the QES team, and Jude Hughes who pointed me in the right directions. In addition Lizette van Heerden (SNZ), Brian Easton, Geoff Bertram, and Dennis Rose all made helpful suggestions, as did people at the presentation at the LEW conference. Naturally I bear responsibility for the views expressed and any errors. 


\section{References}

Australian Bureau of Statistics. (2006). Measuring changes in labour costs. Australian Bureau of Statistics. Retrieved December 12, 2010, from http://www.abs.gov.au/AUSSTATS/abs@.nsf/fe aturearticlesbyCatalogue/15791A6472F5873CC A25723B000ED981?OpenDocument

Conway, P. (1999). An unlucky generation? The wages of supermarket workers post-ECA. Labour Market Bulletin, 23-50.

Jones, C. (1998). Introduction to economic growth (1st ed.). New York: W.W. Norton.

Krugman, P. (1997). The age of diminished expectations: U.S. economic policy in the 1990 s (3rd ed.). Cambridge Mass.: MIT Press.

New Zealand Treasury. (2009). Challenges and Choices: New Zealand's Long-term Fiscal Statement. Presented to the House of Representatives Pursuant to Section $26 \mathrm{~N}$ of the Public Finance Act 1989. New Zealand Government. Retrieved from http://www.purl.org/nzt/o-1243

Rowthorn, R. (1980). Capitalism, conflict and inflation : essays in political economy. London: Lawrence and Wishart.

Statistics New Zealand. (2010a). Industry Productivity Statistics 1978-2008. Statistics New Zealand. Retrieved December 12, 2010, from http://www.stats.govt.nz/browse_for_stats/econo mic_indicators/productivity/industry-level- productivity-1978-2008.aspx

Statistics New Zealand. (2010b). Productivity Statistics: Sources and Methods (Sixth edition). Statistics New Zealand. Retrieved from http://www.census.govt.nz/ /media/Statistics/Pu blications/macro-economic/productivitysources-methods/productivity-sources-andmethods-2009.ashx

Statistics New Zealand. (2010c). Productivity Statistics: 1978-2009. Hot Off The Press (p. 26).

Wellington, New Zealand: Statistics New Zealand. Retrieved from http://www.stats.govt.nz/ /media/Statistics/Bro wse $\% 20$ for\%20stats/ProductivityStatistics/HOT P7809/ProductivityStatistics7809HOTP.ashx

Statistics New Zealand. (2010d). Unadjusted and adjusted LCI comparison. Statistics New Zealand. Retrieved November 10, 2010, from http://www.stats.govt.nz/browse_for_stats/econo mic_indicators/prices_indexes/unadjustedadjusted-lci-comparison.aspx

Statistics New Zealand. (n.d.). SNZ Summary Profile for Information about the National Accounts - Year ended March. Retrieved November 10, 2010, from

http://www2.stats.govt.nz/domino/external/omni /omni.nsf/outputs/National+Accounts++ Year+ended + march

Stiglitz, J. E. (1985). Equilibrium Wage Distributions. The Economic Journal, 95(379), 595-618. 